(昭和 39 年 2 月 10 日受理)

触媒を含浸させたポリビニルアルコール繊維への

酢酸ビニルのグラフト重合

$\begin{array}{lllll}\text { 京都大学工学部高分子化学教室 } & \text { 桜 } & \text { 田 } & \text { - } & \text { 郎 } \\ \text { 甲南大学理学部灾用化学教室 } & \text { 圾 } & \text { 口 } & \text { 康 } & \text { 燨 }\end{array}$

\title{
GRAFT POLYMERIZATION OF VINYL ACETATE ONTO POLYVINYL ALCOHOL FIBERS IMBIBING CATALYSTS.
}

By Ichirō Sakurada* and Yasuyoshi Sakaguchi**

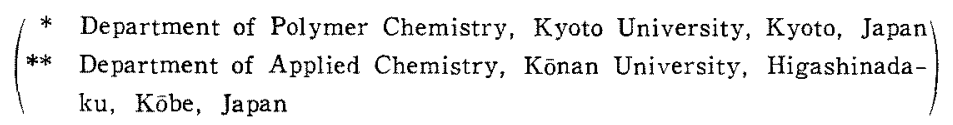

Untreated and heat-treated (at $180^{\circ} \mathrm{C}$ or $225^{\circ} \mathrm{C}$ ) polyvinyl alcohol (PVA) fibers imbibing solutins $(1 \mathrm{~g} / \mathrm{g}$-fiber) of various catalysts were heated with vinyl acetate in sealed tubes for graft polymerization. When potassium or ammonium persulfate were used as catalysts, the grafting proceeded smoothly under suitable conditions, but the efficiencies were generally lower than those in the case of styrene, and were affected by heating temperatures and solvents of the imbibing solutions. In the cases of hydrogen peroxide, the grafting proceded with some ease when water contents of the imbibing solutions were high, but the efficiencies were generally lower than those in the case of persuefates. In the cases of $\alpha, \alpha^{\prime}$-azo-bisisobutylonitrile and benzoyl peroxide, the homopolymerization proceeded predominantly as the grafting scarcely occured.

The grafting was affect to a greater extent than in the case of styrene by heat treatment of raw PVA fibers.

Dry PVA fibers imbibing catalysts were also heated with vinyl acetate-methanol mixtures. The grafting proceeded slightly when fibrous structures were maintained, but proceeded considerably when fibers dissolved in monomer mixtures during the heating. In this case the droducts of about $50 \%$ increased weight dissolved almost comdletely in acetone.

The grafting of vinyl acetate in emulsion states onto PVA fibers were also examined, but no desirable results were obtained.

The difference of grafting behaviors between vinyl acetate and styrene onto PVA fibers was similar to that onto cellulose fibers.

(Received February 10, 1964)

\section{1. 緒言}

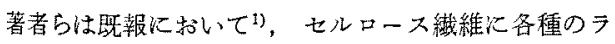

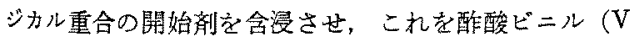
Ac) と加熱してグラフト重合を行な5方法について榆討 した。主心触媒を含浸させたポリビニルアルコール（P VA) 鐵維とスチレン (St) との加熱によるグラフト重 合を険討した2)。このような法によつてグシフト重合 を円滑に進め得ることを認めたので，本報では触媒を含 浸させた PVA 䋐維とVAc の加熱によるグラフト重合 艺陚みた。著者の 1 人模田ら快 PVA 皮膜および瀻維へ
のVAc の放射線ダラフト重合について実験を行ない, VAc は St などに比べてグラフト重合を起こしにくい ことを認めている。試料，辏験方法などは St の場合と 同じであるので，その詳細は略す。

\section{2. 触媒溶液を含浸させた未熟処理繊維 への純酢酸ビニル添加加熱重合}

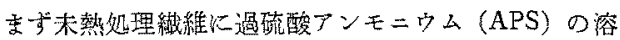
液を $100 \%$ 含浸させ，これに純VAcを添加して封管中 で加熱した。この結果は Table 1 に示すと和りである。 第 1 表ならびにこれと既報の結果との比跤から，次のこ 
Table 1 Graft polymerization of vinyl acetate onto untreated PVA fibers imbibing solutions of ammonium persulfate.

Imbibing solutions $1 \mathrm{~g} / \mathrm{g}$-fiber, Monomer $1.8 \mathrm{~g} / \mathrm{g}$-fiber, Atmosphere air

\begin{tabular}{|c|c|c|c|c|c|c|}
\hline$\underset{\%}{\text { Catalyst }}$ & $\begin{array}{l}\text { Solvent of imbibing } \\
\text { solutions, vol } \%\end{array}$ & $\begin{array}{l}\text { Temp. of } \\
\text { heating, }{ }^{\circ} \mathrm{C}\end{array}$ & $\begin{array}{l}\text { Time of } \\
\text { heating, hr }\end{array}$ & $\begin{array}{l}\text { Weight } \\
\text { increase } \%\end{array}$ & $\begin{array}{l}\text { Degree of } \\
\text { grafting, } \%\end{array}$ & $\begin{array}{l}\text { Graft } \\
\text { efficiency, \% }\end{array}$ \\
\hline 0.3 & Methanol 85-Water 15 & 60 & 70 & 7 & 5 & - \\
\hline " & $" \prime$ & 90 & 3 & 21 & 6 & - \\
\hline 1 & $" \prime$ & 60 & 40 & 16 & 16 & 100 \\
\hline$" \prime$ & $" \prime$ & 60 & 70 & 25 & 23 & 92 \\
\hline$"$ & $"$ & 80 & 6 & 17 & 17 & 100 \\
\hline$"$ & $"$ & 90 & 1 & 32 & 19 & 59 \\
\hline " & $"$ & $" \prime$ & 3 & 50 & 26 & 52 \\
\hline 3 & $" \prime$ & 60 & 20 & 163 & 42 & 26 \\
\hline$"$ & $" 1$ & 90 & 1 & 170 & 56 & 33 \\
\hline 5 & " & 60 & 20 & 175 & 45 & 26 \\
\hline$\prime \prime$ & $" \prime$ & 90 & 1 & 177 & 64 & 36 \\
\hline 1 & Acetone $70-$ Water 30 & 60 & 20 & 5 & - & - \\
\hline$" \prime$ & "' & 90 & 2 & 97 & 35 & 36 \\
\hline
\end{tabular}

Table 2 Graft polymerization of vinyl acetate onto untreated PVA fibers imbibing solutions of hydrogene peroxide.

\begin{tabular}{|c|c|c|c|c|c|c|}
\hline$\underset{\%}{\text { Catalyst }}$ & $\begin{array}{l}\text { Solvent of imbibing } \\
\text { solutions, vol } \%\end{array}$ & $\underset{{ }^{\circ} \mathrm{C}}{\text { Temp. }}$ & $\underset{h r}{\operatorname{Time}}$ & $\begin{array}{l}\text { Weight } \\
\text { increase, \% }\end{array}$ & $\begin{array}{l}\text { Degree of } \\
\text { grasting, } \%\end{array}$ & $\begin{array}{l}\text { Graft } \\
\text { efficiency, } \%\end{array}$ \\
\hline 0.3 & Methanol 99-Water 1 & 60 & 20 & 0 & - & - \\
\hline$"$ & $\prime$ & 90 & 1 & 0 & - & - \\
\hline 1 & Methanol 97 -Water 3 & 60 & 70 & 13 & 13 & 100 \\
\hline$" \prime$ & " & 90 & 3 & 47 & 15 & 32 \\
\hline 3 & Methanol $93-$ Water 7 & 60 & 20 & 4 & - & - \\
\hline$n$ & $" \prime$ & 90 & 1 & 0 & - & - \\
\hline$"$ & $"$ & 90 & 3 & 54 & 12 & 22 \\
\hline 1 & Acetone $83-$ Water 17 & 60 & 20 & 38 & 5 & - \\
\hline$"$ & $\prime \prime$ & 90 & 2 & 5 & - & - \\
\hline
\end{tabular}

とがわかる。VAc のグラフト重合は，七ルロ一スの場 合と同样に, Stよりも起こりにくい。触媒濃度をかな り高めないと重合は起こりにくく、この㑯向はせルャー スーVAc 系々同様である。重合が高度に進んだ点に括け

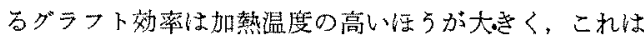
St の場合と巽なり，七ルロースーVAc 系と同じ便向に ある。触媒溶液の溶煤としてメタノール85-水 15 また はマセトン 70-水 30 混合液を用いたときの結果は，大 善ない。

次に過酸化水素 (HP) を触媒に用いてグラフト重合を 陚みた。この結果は Table 2 に示すと特りであり，重 合は一般にきわわて起こりにくい。St の場合にも HP 触媒は APS 触媒よりもグラフト熏合を起こしKくかっ たが、VAc の場台にはこの傾问が著しい。同様なこと はセルロースの場合にも認められた。
次に水に不溶性の触媒である $\alpha, \alpha^{\prime}-$ アジビスイソブチ ロニトリル(AIBN) および過酸化ベンゾイル (BPO)を 用いて同様な実験を行なった。この結果は Table 3 K 示すとおりであり，単独重合はかなり速きかに起こって いるが，グラフト率はいずれの場合も5\%以下儿過ぎな W.

\section{3. 触媒溶液を含浸させた $180^{\circ} \mathrm{C}$ 熱処理 緎維への純酢酸ビニル添加加熱重合}

次に $180^{\circ} \mathrm{C} ， 20$ 分間熱処理絨維について同様な穾験を 行なった。渦硫酸カリウム(KPS)あるいは APS を触 媟に用いた結果㤌 Table 4 のと括りである。

この表からかかるように，触媒の水溶液を含浸させた ときは，既述の含水率の低い触媒溶液を含浸させた未熱 処理繊維よりもグラフト重合がよく進んでいる。しかし 
Table 3 Graft polymerization of vinyl acetate onto untreated PVA fibers imbibing solution of $\alpha, \alpha^{\prime}$-azo-bisisobutylonitrile or benzoyl peroxyd.

\begin{tabular}{|c|c|c|c|c|c|c|c|}
\hline \multicolumn{2}{|c|}{$\begin{array}{c}\text { Catalyst } \\
\%\end{array}$} & \multirow{2}{*}{$\begin{array}{l}\text { Solvent of imbibing } \\
\text { solution, vol \% }\end{array}$} & \multirow{2}{*}{$\frac{\substack{\text { Temp. } \\
{ }^{\circ} \mathrm{C}}}{60}$} & \multirow{2}{*}{$\begin{array}{c}\text { Time } \\
\mathrm{hr}\end{array}$} & \multirow{2}{*}{$\frac{\begin{array}{l}\text { Weight } \\
\text { increase, } \%\end{array}}{40}$} & \multirow{2}{*}{$\begin{array}{l}\text { Degree of } \\
\text { grafting, } \% \\
4\end{array}$} & \multirow{2}{*}{$\frac{\begin{array}{l}\text { Graft } \\
\text { efficiency, \% }\end{array}}{10}$} \\
\hline AIBN & 0.2 & & & & & & \\
\hline & 1 & $" \prime$ & 60 & 20 & 146 & 0 & 0 \\
\hline & $" \prime$ & " & 90 & 1 & 170 & 0 & 0 \\
\hline & $" 1$ & Methanol $85-$ Water 15 & 60 & 20 & 179 & 0 & 0 \\
\hline & $" \prime$ & Acetone 100 & 60 & 20 & 185 & 0 & 0 \\
\hline & $"$ & $"$ & 90 & 1 & 163 & 0 & 0 \\
\hline $\mathrm{BPO}$ & 0.2 & Methanol 100 & 60 & 40 & 3 & - & - \\
\hline & 1 & $" \prime$ & 60 & 20 & 91 & 5 & 5 \\
\hline & $" 1$ & $"$ & 80 & 6 & 129 & 3 & 2 \\
\hline & 0.2 & Methanol 85-Water 15 & 60 & 40 & 0 & - & - \\
\hline
\end{tabular}

Table 4 Graft polymerization of vinyl acetate onto heat-treated $\left(180^{\circ} \mathrm{C}, 20 \mathrm{~min}\right)$ PVA fibers imbibing solutions of persuefates.

\begin{tabular}{|c|c|c|c|c|c|c|c|}
\hline \multicolumn{2}{|c|}{$\begin{array}{c}\text { Catalyst } \\
\%\end{array}$} & \multirow{2}{*}{$\begin{array}{l}\begin{array}{l}\text { Solvent of imbibing } \\
\text { solutions, vol } \%\end{array} \\
\text { Water } 100\end{array}$} & \multirow{2}{*}{$\frac{{ }^{\text {Temp. }} \mathrm{C} .}{60}$} & \multirow{2}{*}{$\frac{\underbrace{\text { Time }}_{h r}}{40}$} & \multirow{2}{*}{$\begin{array}{l}\begin{array}{l}\text { Weight } \\
\text { increase, } \%\end{array} \\
118\end{array}$} & \multirow{2}{*}{$\begin{array}{l}\begin{array}{l}\text { Degree of } \\
\text { grafting, } \%\end{array} \\
35\end{array}$} & \multirow{2}{*}{$\frac{\begin{array}{l}\text { Graft } \\
\text { efficiency, } \%\end{array}}{30}$} \\
\hline KPS & 0.3 & & & & & & \\
\hline$*$ & $" 1$ & " & 90 & 3 & 48 & 25 & 52 \\
\hline & 1 & $"$ & 60 & 40 & 124 & 31 & 25 \\
\hline \multirow[t]{4}{*}{ * } & $" \prime$ & $"$ & 90 & 3 & 154 & 98 & 64 \\
\hline & 3 & $" \prime$ & 60 & 40 & 184 & 69 & 38 \\
\hline & 5 & $"$ & 60 & 20 & 175 & 78 & 45 \\
\hline & $" \prime$ & $"$ & 60 & 40 & 192 & 77 & 40 \\
\hline \multirow[t]{3}{*}{ APS } & 1 & Water 100 & 60 & 40 & 43 & 27 & 63 \\
\hline & $"$ & $"$ & 60 & 70 & 137 & 9 & 7 \\
\hline & 3 & $" \prime$ & 60 & 20 & 155 & 117 & 75 \\
\hline \multirow[t]{4}{*}{$*$} & $" l$ & $\prime \prime$ & 90 & 3 & 156 & 89 & 57 \\
\hline & 5 & $" \prime$ & 60 & 20 & 164 & 75 & 46 \\
\hline & 3 & Methanol $50-$ Water 50 & 60 & 20 & 187 & 50 & 27 \\
\hline & " & Methanol 85-Water 15 & 60 & 20 & 169 & 19 & 11 \\
\hline
\end{tabular}

* Fibers aggletinated.

触某の浴媒としてメタノール85-水 15 の混合液荧用い

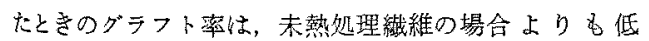
いSt の場合には、溶煤のヌタノール含雨率が高い場 合でも円滑にグラフト重合が起こった。この差買はメタ ノールVAcのに対する莗鎖移動性が大きいこと、VAc

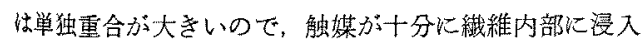
していないと単独重合を起こしやすいことなどに基つくく と考光られる。同様な差異はせルロース瀻維の場合にる 認められたとこるである。

次にHP定触谋に用いて实駼を行なった。この結果は

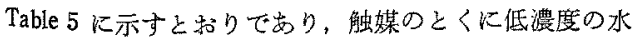
溶葆壳含漫させると，グラフト重合がかなり円滑に起こ
っている。溶媒としてょタノール50-水50 混合液を用 いると，St の場合には円滑にグラフト重合が進んだが， VAc の場合恃重合が進みにくい。

\section{4. 触媒溶液を含浸させた $225^{\circ} \mathrm{C}$ 熱処理 纎維への純酷酸ビニル添加加熱重合}

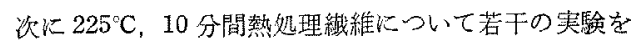
行なった。この結果は Table 6 に示すと怙りであり， 一般に未処現瀻維あるいは $180^{\circ} \mathrm{C}$ 熱処理瀻維に比べてグ

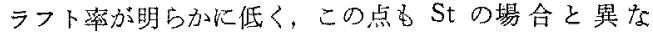
る。VAc はStよりも単独重合性が大きいので，䊼維内 部にモ，マーあるいは触禁が浸入しにくくなるを，VAC 
Table 5 Graft polymerization of vinyl acetate onto heat-treated $\left(180^{\circ} \mathrm{C}, 20 \mathrm{~min}\right)$ PVA fibers imbibing solution of hydrogene peroxide.

\begin{tabular}{|c|c|c|c|c|c|c|}
\hline $\begin{array}{c}\text { Catalyst } \\
\% \%\end{array}$ & $\begin{array}{l}\text { Solvent of imbibinff } \\
\text { solutions, vol } \%\end{array}$ & $\underset{{ }^{\circ} \mathrm{C}}{\operatorname{Temp}}$ & $\operatorname{Time}_{\mathrm{hr}}$ & $\begin{array}{l}\text { Weight } \\
\text { increase, } \%\end{array}$ & $\begin{array}{l}\text { Degree of } \\
\text { grafting. } \%\end{array}$ & $\begin{array}{l}\text { Graft } \\
\text { efficiency, } \%\end{array}$ \\
\hline 0.1 & Water 100 & 60 & 70 & 5 & - & - \\
\hline 0.3 & " & 60 & 20 & 7 & - & - \\
\hline$" 1$ & $" \prime$ & 60 & 70 & 169 & 88 & 52 \\
\hline 1 & " & 60 & 40 & 10 & 9 & - \\
\hline 3 & $" \prime$ & 60 & 20 & 18 & 12 & 67 \\
\hline$" \prime$ & $"$ & 60 & 70 & 178 & 48 & 28 \\
\hline 0.3 & Methanol 50-Water 50 & 60 & 70 & 44 & 10 & 23 \\
\hline
\end{tabular}

Table 6 Graft polymerization of vinyl acetate onto heat-treated $\left(225^{\circ} \mathrm{C}, 10 \mathrm{~min}\right)$ PVA fibers imbibing solutions of different catalysts.

\begin{tabular}{|c|c|c|c|c|c|c|c|}
\hline \multicolumn{2}{|c|}{$\begin{array}{c}\text { Catalyst } \\
\%\end{array}$} & $\begin{array}{l}\text { Solvent of imbibing } \\
\text { solutions, vol } \%\end{array}$ & Temp. & Time & $\begin{array}{l}\text { Weight } \\
\text { increase, } \%\end{array}$ & $\begin{array}{l}\text { Degree of } \\
\text { grafting, } \%\end{array}$ & $\begin{array}{l}\text { Graft } \\
\text { efficiency, \% }\end{array}$ \\
\hline \multirow[t]{3}{*}{ KPS } & 1 & Water 100 & 80 & 6 & 112 & 19 & 17 \\
\hline & 3 & $" \prime$ & 60 & 40 & 176 & 30 & 17 \\
\hline & $" \prime$ & $" \prime$ & 80 & 6 & 100 & 31 & 31 \\
\hline \multirow[t]{4}{*}{ APS } & 1 & Water 100 & 80 & 6 & 182 & 17 & 9 \\
\hline & 3 & $"$ & 60 & 20 & 170 & 36 & 21 \\
\hline & $\prime \prime$ & " & 80 & 6 & 53 & 29 & 55 \\
\hline & $\prime \prime$ & Methanol 85-Water 15 & 60 & 20 & 170 & 6 & 4 \\
\hline \multirow[t]{2}{*}{$\mathrm{H}_{2} \mathrm{O}_{2}$} & 0.3 & Water 100 & 80 & 6 & 138 & 36 & 26 \\
\hline & 1 & $"$ & 80 & 6 & 148 & 22 & 15 \\
\hline
\end{tabular}

Table 7 Graft polymerization of vinyl acetate onto dry PVA fibers imbibing different catalysts. Heating temp. $60^{\circ} \mathrm{C}$

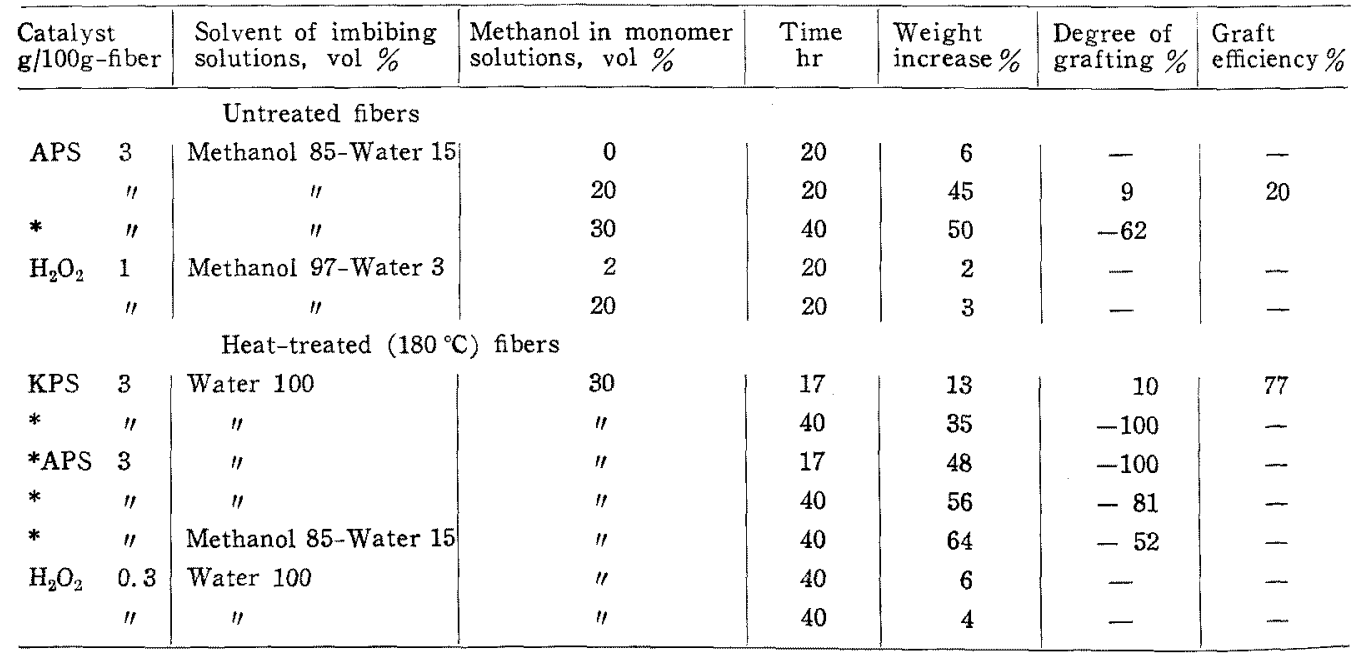

* Fibers almost disolved in monomer mixtures during heating. 
のほうが単独重合がより侵勢に起こるものと思われる。

\section{5. 触媒を含浸させた乾燥䄉維への酢酸} ビニルメタノール混合液添加加熱重合

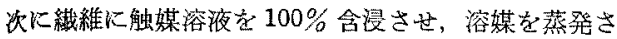
せてから、純 VAc またはVAc-メタノール混合液とと ると加熱した。これに関する結果は一括してTable 7 に 示した。

Table 7 から次のことが放かる。綀VAc 古るいはV V Ac 8ーメタノール2 混合液を添加しても，一般にグラフ 卜重合が進みにくく，またメタノール30 vol \% な含む 溶液を棌加してる，過酸化水素触媒のときにはグラフト 重合は進みにくい。このよ5な傾向はSt の場合と珙な ク，セルロースーVAc 系と同じである。しかし，過硫酸 塩を触媒とし、VAc 7ーメタノール3 浘合液を添加した ときは，加熱特に纎稚のほとんどが混合液に透明に溶解

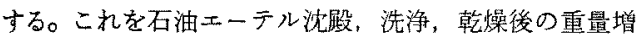
加率は 50\% 程度であるが，乾燥物はアセトン抽出仙上 って大部分が溶出し，この方法によるとグラフト率は真 の值になった。抽出後の緎維減量は触媒を水溶液の形で

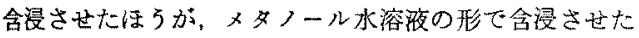
場合よりる大きいようである。このようなアセトンには

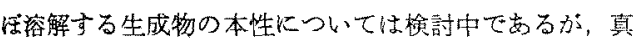
のグラフト共重合物が生成しているものと思われる。

\section{6. 触媒溶液を含浸させた緎維への酢酸}

$$
\text { ビニルエマルジョン添加加熱重合 }
$$

次に触媒水溶液を含浸させた熱処理瀻維にVAc エマ ルジョンを添加して，封管中で静置状で加熱した。この 結果は Table 8 に示すと拈りで，St に比べて一般にグ ラフト重合が起こりにくい。このような傾问はセルロー スの場合にる認められたところでる。

\section{7. 結 語}

以上のよ5に，PVA 㵶維に触媒を含浸させてから酭
Table 8 Graft polymerization of vinyl acetate in emulsion states onto heat-treated $\left(180^{\circ} \mathrm{C}\right)$ PVA fibers imbibing aqueous solutions of catalysts.

Imbibing solutions $1 \mathrm{~g} / \mathrm{g}$-fiber; monomer 1.8 $\mathrm{g} / \mathrm{g}$-fiber; conc. of monomer in emulsions 20 vol ; Heating $60^{\circ} \mathrm{C}, 40 \mathrm{hr}$

\begin{tabular}{|c|c|c|c|c|}
\hline $\begin{array}{c}\text { Emulsifier } \\
\%\end{array}$ & \multicolumn{2}{|c|}{$\begin{array}{c}\text { Catalyst } \\
\%\end{array}$} & $\begin{array}{l}\text { Weight } \\
\text { increase \% }\end{array}$ & $\begin{array}{l}\text { Degree of } \\
\text { grafting, } \%\end{array}$ \\
\hline$A * 0.5$ & KPS & 1 & 73 & 23 \\
\hline$"$ & $\mathrm{H}_{2} \mathrm{O}_{2}$ & 0.5 & 16 & 6 \\
\hline$A * 2$ & KPS & 1 & 120 & 30 \\
\hline " & $\mathrm{H}_{2} \mathrm{O}_{2}$ & 0.5 & 128 & 28 \\
\hline $\mathrm{B}^{*} 2$ & KPS & 1 & 13 & 2 \\
\hline$" \prime$ & $\mathrm{H}_{2} \mathrm{O}_{2}$ & 0.5 & 15 & 5 \\
\hline
\end{tabular}

* A. Polyethylene glycol oleyl ether;

B. Polyethylene glycol lauryl ether

酸ビニルとともに加熱すると，適当条件ではグラフト重 合がかなり円滑纪進も。しかし，グラフト重合は一般に スチレンの場合よりも進みにくく，この傾向は $\mathrm{H}_{2} \mathrm{O}_{2}, \mathrm{~B}$ PO，AIBN を触媒に用いた場合飞著しい。またスキレ ンの場合に比べて，一般にメタノールによつて重合が抑 制されやすい。このような䣫酸どニルとスチレンのグラ フト学動の差異は，七ルロース維維の場合と同様であ る。ただし，過酼酸塩含漫瀻維を酶酸ビニル7ーメタ， ール3混合液と加熱した場合，七ルロースの場合は水が 其存しないとグラフト重合はきかめて起こりにくかつた が，PVA の場合は㵶維が结ぼ溶解し，生成物は重量增 加率が $50 \%$ 程度で京るが，ア七下ンに大部分溶解した。

种記：原料 PVA 㵶維の提供にあずかつた大日本紡績 株式会社坂越工場汇感謝する。

\section{文献}

1）桜田一郎，圾口康義，酒井保伊; 瀻学誌，投稿中

2) 桜田一郎, 坂口承義; 䋐学誌, 投稿中

3) 桜田一郎, 网田紀夫, 久語栄子; 同位体乙放射線 2. $316(1959)$ 